Língua e Literatura, n. 21, p. 19-27, 1994/1995.

\title{
A CONSTRUÇÃO DO SENTIDO: UM EXEMPLO FOTOGRÁFICO PERSUASIVO
}

\section{Beth Brait*}

"Mais que a exploração dos poderes da linguagem, a imagem mesmo falsa é verdadeira"

Rubem Fonseca

“O emprego dos discursos persuasivos tem por objetivo um julgamento, pois, sobre uma questão conhecida, julgada, não há necessidade de discorrer"

Aristóteles

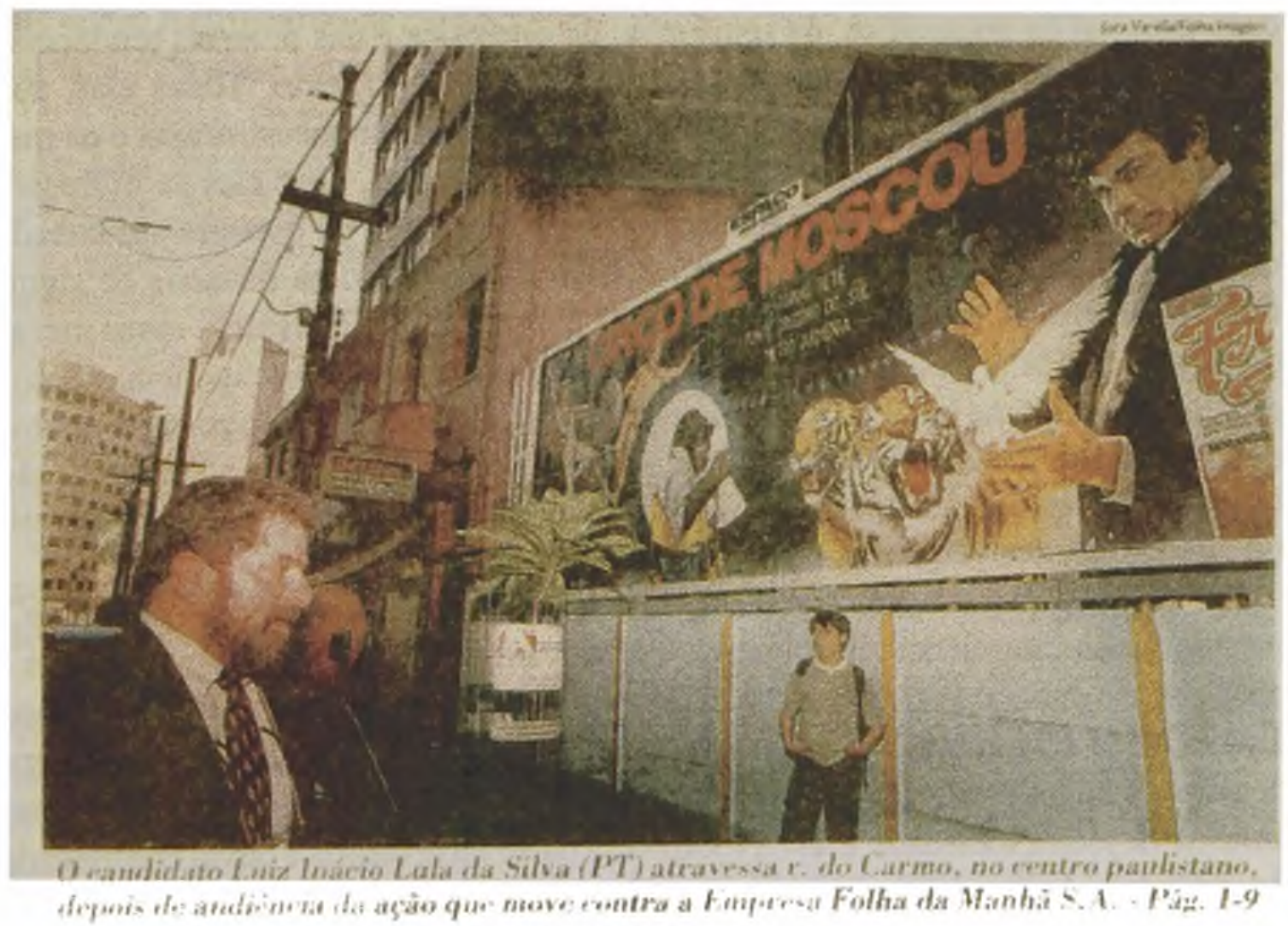

(*) Professora da Universidade de São Paulo. 
RESUMO: Ainda que os estudos sobre a argumentação e a persuasão estejam mais amplamente desenvolvidos no que diz respeito à linguagem verbal, o discurso visual pode também oferecer excelentes exemplos de construção ambígua do sentido, graças a processos especificos de produção enunciativa. Neste artigo, o objetivo $t$ mostrar alguns aspectos enunciativos-discursivos que possibilitam transformar uma fotografia, aparentemente objetiva, em texto, em discurso fotográfico persuasivo.

Palavras-chave: construção de sentido, enunciação, persuasão, fotojornalismo.

A linguagem, como se sabe, é sempre, em maior ou menor grau, uma forma de persuasão, de levar o outro a aderir a um ponto de vista. Como testemunhas, podemos arrolar os diferentes discursos que nos cercam no dia-a-dia, e com os quais nos envolvemos como participantes ativos, tanto da perspectiva da produção quanto da recepção, de maneira mais ou menos consciente.

Várias disciplinas podem oferecer elementos para uma reflexão a respeito das formas que a linguagem engendra para circunscrever e caracterizar um ato persuasivo. Dentre elas, podemos destacar as contribuições da Retórica, a velha e a nova, e dos diferentes estudos contemporâneos sobre a enunciação, como é o caso especial da pragmática, da semântica, da semiótica e das diversas tendências englobadas sob o título análise do discurso e análise do texto. Todas elas, sob diferentes enfoques, procuram descrever, analisar e explicar as estruturas e os mecanismos produtores da dimensão persuasiva do discurso, quer eles se ofereçam como ameaçadores, sedutores, dissimulados, apresentados de maneira sofisticada ou grosseiramente convincentes. Atravessando e integrando os sistemas de significação, as formas de produção de sentido e a estruturação de textos, esses mecanismos mobilizam nossa memória, nosso imaginário, nossa inteligência, nossos desejos e, de alguma maneira, conduzem, conquistam, forçam ou constroem pontos de vistas sobre o mundo. Portanto, seja qual for a teoria que os focalize, a relação linguagem-ideologia, linguagem-sistema de valores, linguagem-pragmática constitui o ponto de convergência dos estudos.

Quando lemos numa revista "Quem inventou esse sutiã merece um busto", mesmo tendo consciência do objetivo exclusivamente comercial da mensagem conquistar o público feminino para um novo modelo de porta-seios-, não resistimos à sedução do slogan, aderindo, senão às novidades da peça íntima que ele apresenta, à lúdica sugestão de que esse acontecimento merece a homenagem e o reconhecimento de toda a sociedade, efeito produzido a partir da divertida e óbvia criatividade do jogo de palavras centrado no termo "busto"

Mas também podemos avaliar, como receptores e como analistas, outras formas de persuasão. E em tempos de campanha política, por exemplo, é impossível 
BRAIT, Beth. A construção do sentido: um exemplo fotográfico persuasivo. Língua e

Literatura, n. 21, p. 19-27, 1994/1995.

não observar como candidatos e simpatizantes de diferentes partidos recorrem às mesmas estratégias para configurar um percurso que os alce ao poder. Dada a diversidade do eleitorado, a conveniência dos tempos e o longo e difícil caminho em direção ao objeto do desejo, eles atuam camaleonicamente, despindo-se, sempre que necessário, dos atributos que os localizam social, cultural e ideologicamente.

$O$ que significa, entretanto, persuadir por meio da linguagem, quer ela seja verbal ou não? Que mecanismos participam do fazer persuasivo de um enunciador e, conseqüentemente, do fazer interpretativo de um enunciatário?

É precisamente em função dessas questões que procuraremos analisar uma foto de jornal e sua legenda ${ }^{1}$, conjunto exposto como informativo, referencial, mas que de fato funciona como construção persuasiva, como um direcionamento de sentido a partir de sua forma de enunciação. Alguns instrumentos teóricos oferecidos pela retórica e pela semântica da enunciação estarão mobilizados nessa análise, oferecendo também a oportunidade do ligeiro esboço de um percurso teórico, configurado pelos estudos da persuasão.

Um rapidíssimo resumo do longo percurso efetuado pela retórica antiga e pela abordagem contemporânea da dimensão persuasiva da linguagem ajudar a entender $o$ interesse pela argumentação como valorização da linguagem não unicamente como instrumento de representação, comunicação e expressão, mas também como forma de ação sobre o outro.

A retórica, disciplina que liderou os estudos da linguagem durante séculos, caiu em desgraça a partir do momento em que se transformou em mera vulgarizadora de estereotipadas técnicas de "embelezamento do texto", mas foi redimida na segunda metade do século XX. Essa revalorização se deu a partir de um novo dimensionamento da preocupação com o domínio da expressão verbal ligada à argumentação, à estruturação do discurso, ao exercício do poder via palavra. Paralelas às diferentes vertentes da poética, as teorias lingüísticas construídas em torno da enunciação participam do redimensionamento não apenas do estudo das figuras de linguagem, mas da descrição dos processos argumentativos. E são esses estudos que oferecem boa parte do instrumental para a abordagem da organização discursiva marcada por procedimentos que caracterizam a persuasão, que objetivam a adesão a um ponto de vista.

$O$ interesse pela argumentação, pela retórica dos conflitos não é novo. Como observa Alain Lempereur (1991), estava nos sofistas do século V A.C., que se esmeravam em ensinar a argumentação com a finalidade de conquistar a adesão dos mais diversos auditórios; mereceu de Aristóteles um tratado inteiro sobre a arte de persuadir, que segundo o filósofo exige o domínio da razão, das paixões e do estilo;

(1) Foto apresentada no inicio deste artigo. 
BRAIT, Beth. A construção do sentido: um exemplo fotográfico persuasivo. Língua e Literatura, n. 21, p. 19-27, 1994/1995.

perdurou no pragmatismo romano, como se observa num Cícero e num Quintiliano; e hesitou, em muitos momentos, entre a sinonímia e a não sinonímia retórica-argumentação.

O Tratado da argumentação ou Nova retórica, de Perelman, publicado em 1958, reata o par retórica-argumentação, subordinando os fenômenos lingüísticos à vontade de convencer. "A teoria da argumentação, desenvolvida na retórica antiga que conheceu um grande sucesso no Renascimento, sofreu um declínio a partir do século XVII, sob a influência das teses do racionalismo e do empirismo. A importância dada no século XX à filosofia da linguagem e à filosofia dos valores contribui para o renascimento da teoria da argumentação, cujos efeitos se revelaram especialmente relevantes na renovação dos estudos do raciocínio juridico e filosófico"(PERELMAN, 1986:264).

Essa teoria da argumentação, segundo o mesmo autor, "consiste numa reação numa reação contra os esforços dos lógicos modernos, que, na tentativa de renovar a lógica através da análise do raciocínio das matemáticas, identificaram a lógica com a lógica formal (...) Argumentar é fornecer argumentos, ou seja, razões a favor ou contra uma determinada tese. Uma teoria da argumentação, na sua concepção moderna, vem assim retomar e ao mesmo tempo renovar a retórica dos gregos e romanos, concebida como a arte de bem falar de modo a persuadire a convencer, e retoma a dialética e a tópica, artes do diálogo e da controvérsia" (PERELMAN, 1986:234).

É importante observar que a oposição à lógica formal se dá a partir da concepção de que, nessa perspectiva, todo sistema dedutivo se apresenta como isolado do contexto, enquanto que a argumentação é necessariamente situada, exigindo, para ser eficaz, um contato entre sujeitos. Nesse sentido, a nova retórica considera que a argumentação é essencialmente comunicação, diálogo, discussão, e como tal propõe-se a exercer uma ação qualquer sobre um auditório, modificando a intensidade de sua adesão a certas teses, incitando a uma ação imediata ou ao menos predispondo a uma ação.

Mesmo deixando de lado a riqueza dos trabalhos feitos no âmbito dessa nova retórica, podemos extrair daí alguns aspectos que importam ao recorte aqui empreendido.

O primeiro é que esses estudos contribuem para a consciência de que a argumentação assume formas variadas, podendo produzir efeito persuasivo, sobre o ouvinte ou o leitor, por meio do mascaramento do artifício que configura o produto. Na verdade, a produção de um discurso persuasivo exige do produtor uma elaboração que possibilite à linguagem ser confundida com a realidade, que permita ao discurso assumir a condição de verdade.

Essa postura diante da argumentação e de seus efeitos persuasivos pode servir de suporte para as configurações assumidas pelo discurso persuasivo não verbal, como é o caso da foto escolhida para análise. 
A foto, que apareceu na primeira página do jomal Folha de S. Paulo do dia 24 de maio, e cujo colorido predominante é o vermelho, diz respeito a um acontecimento que, como esclarece a legenda, se deu na rua do Carmo, centro da cidade de São Paulo, depois da audiência de uma ação movida pelo então candidato do PT à presidência, Luiz Inácio Lula da Silva, contra a empresa Folha da Manhã. A foto, inserida num órgão informativo, tem aparentemente a função de ilustrar a notícia, assumindo a condição de discurso jornalístico. Sendo assim, se não estivessem em jogo as formas que o discurso assume para expor e mascarar sentidos, poderíamos entendê-la como um flagrante da passagem de Lula por uma rua do centro da cidade. E nada mais.

Mas de imediato é preciso lembrar que o texto jornalístico é "uma forma objetivante de narrar o cotidiano, mas que necessariamente passa pela forma subjetivante imposta pela constituição de um discurso", como afirma Landowski (1989). Essa tensão, constantemente entretecida, dimensiona também o texto jornalístico como discurso cuja natureza não desfaz o intercâmbio entre comunicação, persuasão e adesão.

Com o apagamento do sujeito que flagrou a cena, uma vez que a técnica fotográfica assegura o simulacro visual do acontecimento, cria-se o efeito de objetividade, de transparência, como se não houvesse um enunciador. Entretanto, a construção da cena enunciativa revela a existência de um sujeito da enunciação, na medida em que o enquadramento, o dimensionamento da luz, e outros recursos da linguagem fotográfica funcionam discursivamente, isto é, não têm um valor em si, enquanto signos de um sistema de comunicação e significação, mas assinalam escolhas de um sujeito, tendo em vista o discurso a ser construído e os efeitos de sentido que devem ser produzidos no enunciatário.

A foto aqui considerada como um texto, coloca em destaque, e em conseqüente relação, duas figuras, ou dois sujeitos como se poderia dizer em linguagem fotográfica:

a) no canto inferior esquerdo, o então candidato do PT à presidência, de perfil, deixa ver apenas uma parte de seu tronco, dirigindo o olhar, aparentemente, para o que está à sua frente;

b) à sua frente, dominando grande parte da cena, um anúncio do Circo de Moscou projeta-se do canto superior direito para o meio da foto. Flagrado num out door, sob o qual está um anônimo popular que parece dirigir o olhar ao candidato, esse anúncio, por força da iluminação, tem como foco principal e dominante a clássica figura do mágico que retira pombas da cartola, um ilusionista ladeado por tigres. Sob o signo do "Circo de Moscou". e numa posição transversalmente superior, a figura dirige um sinistro olhar para o foco observador.

Vamos considerar, primeiramente, um lugar-comum desde Saussure e Jakobson " a forma e o sentido de um elemento semiótico lhe são atribuidos por todos os 
BRAIT, Beth. A construção do sentido: um exemplo fotográfico persuasivo. Língua e Literatura, n. 21, p. 19-27, 1994/1995.

demais elementos com os quais ele se associa paradigmaticamente, em nossa competência, e sintagmaticamente, na sua vizinhança imediata dentro de dado enunciado concretamente realizado por certa performance; o que equivale a dizer (...) que o sentido e a forma de um elemento não são propriedades suas, são, isso sim propriedades estruturais da relação" (LOPES, 1986: 20).

Sob essa perspectiva, a geração de sentido nessa foto passa, necessariamente, pelo tipo de relação que se estabelece entre os dois principais elementos focalizados: o candidato do PT e o Circo de Moscou. Mobilizando paradigmas, contextos pressupostos, estereótipos, a configuração espacial possibilita a associação, por contaminação de traços de significação, do discurso político do PT, simbolizado por sua mais expressiva metonímia -Lula (metonímia, nessa foto, inclusive no plano de expressão: parte da figura) e traços caracterizadores do discurso circense, da arte da ilusão advinda, nesse caso, de Moscou.

A tonalidade avermelhada predominante na foto, e que recobre o rosto de Lula e as palavras "Circo de Moscou", assim como a figura do anônimo popular, interposta entre os dois sujeitos focalizados, são elementos que compõem uma cena enunciativa em que a analogia é o procedimento retórico que confere coerência à mensagem e produz um efeito de sentido suficientemente forte para desestabilizar a função meramente informativa, ilustrativa, dessa foto.

A relação analógica, sitagmaticamente estabelecida pelo texto visual, entre "Lula" "Circo", "Moscou", "Ilusionismo", "vermelho", elementos mediados pelo "anônimo popular", articula e reinstaura um paradigma ideológico, com todas as nuances trabalhadas historicamente pelo imaginário ocidental capitalista.

Como sabemos, a analogia estabelece uma semelhança parcial de caracteres que pode servir de base a uma comparação e, ainda, ser empregada como argumentação, como estratégia persuasiva. A comparação implícita é sempre uma analogia a espera de que o leitor a descubra e interprete ou, ao menos, a usufrua pelas vias do subconsciente. Num artigo intitulado "Analogia e metáfora", Perelman esclarece que o argumento por analogia "consiste na aproximação de dois domínios heterogêneos, cujo primeiro par, a que chamamos de tema, se desejaria esclarecer, precisar ou avaliar graças ao segundo, qualificado de foro da analogia (PERELMAN,1986:207).

Considerando a figura do candidato do PT como tema, objeto a ser esclarecido, avaliado, e o out door como foro, o elemento esclarecedor e avaliador, observamos que os dois domínios heterogêneos são postos em relação de analogia, de similitude, produzindo um efeito de realidade que está reiterado constitutivamente na dimensão de "realidade sem interposição" criada pela mensagem fotográfica.

Se a persuasão é uma forma de argumentação que tem por finalidade convencer, estimular, atingir um objetivo determinado, incentivando os destinatários da mensagem a realizar uma determinada ação, a reagir positivamente à tese que está 
Literatura, n. 21, p. 19-27, 1994/1995.

sendo exposta, podemos concluir que essa foto, pela analogia marota, é uma foto com finalidades persuasivas. Ela procura levar aquele que olha a acreditar na similitude "Lula/Circo/Moscou/llusão", reativando fantasmas aparentemente afastados, mas facilmente reabilitáveis.

Se até aqui nos interessou reter aspectos relativos às formas desenvolvidas pelo discurso para levar sujeitos a aderir a um ponto de vista, é a Oswald Ducrot que devemos recorrer para complementar essa análise. Uma de suas grandes contribuições reside precisamente no estudo da natureza argumentativa da linguagem, apontando tanto para os aspectos que dizem respeito ao papel dos implícitos, quanto à dimensão polifônica da enunciação.

Implicitar ou explicitar conteúdos significa, para Ducrot, fazer passar valores e através deles convencer o enunciatário. Em sua teoria, a pressuposição é mostrada como elemento constitutivo da língua, desempenhando um papel essencial " $n a$ grande comédia da fala", como ele mesmo afirma (DUCROT, 1977: 60). Sob essa perspectiva, as escolhas dos pressupostos limitam a liberdade do destinatário, isto é, o aprisionam num determinado universo. O pressuposto é apresentado como "comum aos dois personagens do diálogo, como objeto de uma cumplicidade fundamental que liga entre si os participantes do ato de comunicação" (DUCROT, 1969:36). O emprego retórico da pressuposição, por sua vez, visa a mobilizar um conteúdo pressuposto, constituído por crenças e conhecimentos presumidos, configurando um uso persuasivo-argumentativo. Sempre segundo Ducrot, o ato de pressupor é uma tática argumentativa em que o enunciador leva o enunciatário a admitir o conteúdo pressuposto, impondo-lhe, a a partir daí, a adesão.

A outra forma de implícito, que é o subentendido, só aparece ligado à enunciação, ao componente retórico, constituindo uma opção de organização do discurso e produzindo efeitos de sentido que surgem na interpretação, que resultam do reconhecimento das razões do enunciador em dizer o que diz.

Juntamente com esses conceitos, as reflexões sobre as características, condições e consequente constituição de efeitos de sentido caminham, na perspectiva de Ducrot, para a idéia de que mesmo num enunciado isolado é possível detectar mais de uma voz. Dentre as marcas da enunciação comportadas pelo enunciado estão as que dizem respeito aos atores eventuais da enunciação, ou seja, a atribuição da origem da enunciação a um ou vários sujeitos, e a distinção entre locutores e enunciadores.

O locutor, similar ao narrador apresentado na teoria narrativa de Genette, é uma entidade do discurso, que não se confunde com o sujeito falante, e que é tido como o responsável pelo dizer. $\mathrm{O}$ enunciador, que também pode ser comparado ao que Genette denomina "centro da perspectiva". distingue-se tanto do locutor quanto do sujeito falante, caracterizando-se por ser uma figura da enunciação, representante do ponto de vista sob o qual o acontecimento é apresentado. 

Literatura, n. 21, p. 19-27, 1994/1995.

Essa teoria importa aqui na medida em que está articulada com a teoria da argumentação, concebida por Ducrot e Anscombre (1976), e que localiza a argumentatividade na própria língua. Nessa articulação está implicado o conceito de "topos", definido como o princípio comum, aceitável pela comunidade em que estão inseridos locutor e alocutário. É sob esse ponto de vista que a argumentação é concebida como dimensão que se apóia nas crenças da coletividade, nos seus sistemas de valores.

Se essas afirmações estão profundamente trabalhadas no que diz respeito à linguagem verbal, como atestam os trabalhos de Ducrot, Anscombre e inúmeros discípulos, não é impossível, respeitadas as diferenças, transferir alguns aspectos para o texto persuasivo de caráter visual que estamos observando, considerando o posto e os pressupostos que possibilitam a compreensão da mensagem, os conteúdos que fazem passar os valores e, através deles, pretendem convencer o enunciatário. Sendo a estratégia persuasiva uma forma de argumentação, o aspecto comum evocado pelo "topos" explica o caráter coercitivo do discurso, uma vez que ele está assentado em crenças comuns, ou mais especificamente, na ideologia, definida por Ducrot como um conjunto de "topoi"

A explícita relação visual entre o candidato do PT e o Circo de Moscou, embora motivada pelo espaço discursivo, é oferecida como um dado de realidade. Os implícitos funcionam como elementos que estabelecem a parceria entre a produção e a recepção e, como conseqüência, funcionam como elemento de adesão à tese que está sendo exposta. Ainda que essa tese tenha utilizado a parceria do acaso, funcionando como uma "blague", a dimensão persuasiva do panfleto estereotipado se institui. $\mathrm{O}$ "topoi" do "ilusionismo vermelho", da "farsa circense originária de Moscou", reabilita-se, ressurge enquanto sabedoria coletiva, casualmente flagrada.

Uma análise da dimensão persuasiva do discurso deve levar em conta, portanto, os traços que permitem reconhecer uma certa intenção do enunciador, os efeitos de sentido visados pelo texto, pelo discurso produzido por esse enunciador e pelo locutor ou locutores por ele instituídos, e a manipulação que o enunciador pretende exercer sobre aquele a quem o discurso se destina. A delimitação dos processos de persuasão implicam a exploração do jogo de imagens que o enunciador constrói de si mesmo, no caso a instituição jornalística empenhada em revelar os fatos, do enunciatário, no caso o leitor que deve receber a informação, formar sua opinião e mudar suas atitudes, e, ainda, do tipo de fazer a que o enunciatário está sendo induzido.

E são esses fatores que desempenham um papel fundamental na constituição dos valores que sustentam um texto e que, no caso específico da foto analisada, travestem, pela enunciação, uma notícia fotográfica, em princípio objetiva, ingênua e inócua, em sutil instrumento de reiteração de pressupostos e crenças coletivas sobre um ponto de vista político, econômico e social. 
BRAIT, Beth. A construção do sentido: um exemplo fotográfico persuasivo. Língua e

Literatura, n. 21, p. 19-27, 1994/1995.

\section{BIBLIOGRAFIA}

DUCROT, Oswald (1969) "Presupposés et sous-entendus" Langue Française 4. Paris, Larousse.

DUCROT, Oswald (1977) Princípios de semântica lingüística (dizer e não dizer). São Paulo, Cultrix.

DUCROT, Oswald (1987) "Esboço de uma teoria polifônica da enunciação". In: O dizer e o dito. Trad. Eduardo Guimarães. Campinas, Pontes. p.161-218.

LANDOWSKI, Eric (1989) La societé réfléchie. Paris, Seuil.

LEMPEREUR, Alain (éd.) (1991) L'argumentation. Liège, Mardaga.

LOPES, Edward (1986) Metáfora: da retórica à semiótica. São Paulo, Atual.

PERELMAN, C. (1986) “Argumentação" e "Analogia e metáfora”. In: Oral/Escrito-Argumentação. Enciclopédia EINAUDI, VOL.2. Lisboa, Imprensa Nacional-Casa da Moeda. p. 234-265; 207-217.

RÉSUMÉ: Même si les études sur l'argumentation et sur la persuasion ont été plus largement développées en ce qui concerne le langage verbal, les discours visuels peuvent aussi présenter excellentes exemples d'effet de sens ambigu, grâce à certaines particularités énonciatives. Cet article cherche de signaler quelques aspects énonciatifs-discursifs qui changent une photo, apparemment objective, en texte, en discours photographique persuasif.

Mots-clés: construction du sens, énonciation, persuasion, photojournalisme. 